\title{
Modeling of feed additives for poultry, with the inclusion of probiotic strains
}

\author{
Galina Zelenkova ${ }^{1,}$, Alexey Zelenkov ${ }^{1,2}$, Antonina Pahomova $^{3}$ and Alexander Pakhomov ${ }^{4}$ \\ ${ }^{1}$ Don State Technical University, sq. Gagarina, 1, 344003 Rostov-on-Don, Russia \\ ${ }^{2}$ Ministry of Agriculture and Food of the Rostov region, Krasnoarmeyskaya st., 33, 344010 Rostov- \\ on-Don, Russia \\ ${ }^{3}$ Platov South-Russian State Polytechnic University (NPI), Novocherkassk, Russia \\ ${ }^{4}$ Don State Agrarian University, o. Persianovsky, 346493, Russia
}

\begin{abstract}
The distribution of feed containing probiotics is one of the most attractive trends in modern animal husbandry for consumers. The introduction of a live component makes the feed not only more effective, but also reduces the content of toxic components, making animal products more environmentally friendly. However, the introduction of viable cells of beneficial microorganisms into the feed significantly increases the requirements for the level of feed design, which in turn forces the development of new, unusual algorithms for such design for zootechnics. First of all, the development of feed additives with the inclusion of probiotic strains should be carried out only taking into account the specific application (type of animal of agricultural significance) and the extent to which the studied microorganisms and the substrate for microbial fermentation are suitable for this animal. The most important issue in this regard is the interaction of the living component with the inanimate one. At a minimum, substances that are part of probiotic feeds and feed additives should not inhibit the growth of target microorganisms. The ideal option is the ability to stimulate their growth or prebiotic activity. Keywords: model, feed additives, poultry, probiotic strains, laying hens, repair young chickens
\end{abstract}

\section{Introduction}

The search and testing of new cheap and environmentally safe feed additives that increase the productivity of poultry, have a positive impact on its health, increase the safety of livestock and increase productivity, is an urgent problem of modern poultry farming.

Today, a wide range of various feed additives, preparations, vitamin and mineral premixes has been developed for poultry, but the task of designing effective probiotic preparations for veterinary use, optimized for a living organism and specific application tasks, has not yet been solved.

The distribution of feed containing probiotics is one of the most popular trends in modern poultry farming. The introduction of a live component makes the feed not only

\footnotetext{
*Corresponding author: zelenkovalex@rambler.ru
} 
more effective, but also reduces the content of toxic components, making poultry products more environmentally friendly.

First of all, the development of feed additives with the inclusion of probiotic strains should be carried out only taking into account the specific application (type of poultry and its purpose) and the extent to which the studied microorganisms and the substrate for microbial fermentation are suitable for this bird. The most important issue in this regard is the interaction of the living component with the inanimate one. At a minimum, substances that are part of probiotic feeds and feed additives should not inhibit the growth of target microorganisms. The ideal option is the ability to stimulate their growth or prebiotic activity.

\section{Materials and Methods}

Probiotics are attractive for use in animal husbandry due to their ability to stimulate growth and prevent animal infections. The developed feed additives use two strains of probiotic bacteria Bacillus subtilis and Bacillus amyloliquefaciens.

Bentonite was used as one of the components of the feed additive.

Industrial reserves of bentonite clays in the Rostov region exceed 200 million tons and are among the most powerful in the world. Bentonites are colloidal clays of volcanic origin, consisting mainly of minerals of the Montmorillic group (up to 90\%), including sodium, magnesium, calcium and aluminum salts of silicic acid. The porous structure containing active exchange cations determines the unique adsorption, cation exchange, and catalytic properties of these minerals, which are both highly acid-resistant and thermally stable. The presence of a complex of biologically active substances in the bentonite clay is of great importance. It contains from 30 to 40 mobile forms of macro-and microelements. The largest specific mass among them is occupied by oxides of silicon, aluminum, iron, calcium, magnesium, sodium, potassium and phosphorus, as well as trace elements-copper, zinc, manganese, cobalt, iodine, etc. At the same time, the clay contains no arsenic, bismuth, mercury, antimony. As an active sorbent, bentonite adsorbs alkaloids, toxins, some microorganisms, harmful metabolic products and removes them from the body.

The principle of solid-phase fermentation, implemented in the development of feed additives, is a cost-effective method for converting food by-products or readily available natural raw materials into probiotic feed additives for poultry. This is a fermentation process carried out on an insoluble carrier material, a source of nutrients, in the absence of a liquid phase, and it may be preferable to liquid-phase fermentation due to higher yields and better characteristics of the resulting product.

When developing the composition of feed additives, it was taken into account that the needs of laying hens and repair young animals in the mineral components that come with the feed are different. In general, the following components were used:

- waste content from filters of the oil extraction industry, containing residues of vegetable oil, phosphates, fatty acids);

- ecobentokorm (similar to bentonite clay);

- probiotic preparations based on the Bacillus subtilis strain - content of viable spores $10^{10}-10^{11} \mathrm{CFU} / \mathrm{g}$, based on the Bacillus amyloliquefaciens strain-content of viable spores $10^{9}-10^{10} \mathrm{CFU} / \mathrm{g}$;

- synthetic preparations of fat-soluble vitamins-A, $D_{3}, E$.

The developed technological scheme involves combining the components of the supplement and probiotic preparations immediately before feeding the poultry, according to the developed algorithm, the effect of such an active component of the feed additive as bentonite on the growth and survival of the target strains was tested.

Two variants of bentonite were used: pure bentonite and bentonite after being used as a filter for sunflower oil purification. 
To determine the number of microorganisms in bentonite, $1 \mathrm{~g}$ of the test powder was ground in $10 \mathrm{ml}$ of sterile water until a homogeneous suspension was formed, from which a series of successive dilutions was prepared and then sown on a solid culture medium LB and on soy agar. Incubated at a temperature of $37^{\circ} \mathrm{C}$ for one day.

To determine the toxicity of bentonite to bacteria of the genus Bacillus, both types of bentonite were sterilized at a temperature of $120^{\circ} \mathrm{C}$ for 20 minutes. Then each of the bentonite types was ground in sterile water $(2 \mathrm{ml}$ of water per $1 \mathrm{~g}$ of bentonite) until a homogeneous suspension was obtained, which was subsequently mixed with soy agar at a concentration of $1,2,5,5,10,20,50 \%$. The resulting nutrient medium was poured into Petri dishes, the control was soy agar without the addition of bentonite.

Suspensions of B. subtilis bacteria (MacFarland turbidity 0.7 , corresponding to about $2 \cdot 10^{8} \mathrm{CFU} / \mathrm{ml}$ ) or B. amyloliquefaciens (MacFarland turbidity 1.9 , corresponding to about $5 \cdot 10^{8} \mathrm{CFU} / \mathrm{ml}$ ) were prepared. From the obtained suspensions, a number of successive dilutions were prepared and seeding was performed from the fifth and sixth dilutions. The cups were incubated for 1 day at a temperature of $36^{\circ} \mathrm{C}$ or $42^{\circ} \mathrm{C}$. To continue to produce the counting of colonies from the fifth breeding.

\section{Results}

Both types of bentonite were seeded with different types of bacteria at concentrations of $5 \times 102$ and $3 \times 102$, respectively, for pure bentonite and bentonite after oil filtration. The bacteria had different colony forms, and belonged to different Gram-positive and Gramnegative species.

Data on the effect of bentonite on bacteria of the genus Bacillus are presented in Tables 1 and 2 .

Table 1. Effect of bentonite in different concentrations on the growth of $B$. subtilis, number of colonies per cup

\begin{tabular}{|c|c|c|c|c|}
\hline Concentration, \% & \multicolumn{2}{|c|}{ Pure Bentonite } & \multicolumn{2}{c|}{$\begin{array}{c}\text { Bentonite after sunflower oil } \\
\text { filtration }\end{array}$} \\
\cline { 2 - 5 } & $36^{\circ} \mathrm{C}$ & $42^{\circ} \mathrm{C}$ & $36^{\circ} \mathrm{C}$ & $42^{\circ} \mathrm{C}$ \\
\hline 0 & $23 \pm 5$ & $22 \pm 2$ & $26 \pm 3$ & $19 \pm 3$ \\
\hline 1 & $21 \pm 4$ & $20 \pm 4$ & $20 \pm 2$ & $23 \pm 5$ \\
\hline 2.5 & $20 \pm 3$ & $24 \pm 3$ & $12 \pm 5^{*}$ & $13 \pm 6^{*}$ \\
\hline 5 & $25 \pm 3$ & $24 \pm 5$ & $0^{*}$ & $0^{*}$ \\
\hline 10 & $26 \pm 4$ & $21 \pm 4$ & $0^{*}$ & $0^{*}$ \\
\hline 20 & $21 \pm 5$ & $27 \pm 5$ & $0^{*}$ & $0^{*}$ \\
\hline 50 & $18 \pm 3$ & $24 \pm 3$ & $0^{*}$ & $0^{*}$ \\
\hline
\end{tabular}

* significant difference from the control $(\mathrm{p}<0.05)$

Table 2. Effect of bentonite in different concentrations on the growth of $B$. amyloliquefaciens number of colonies per cup

\begin{tabular}{|c|c|c|c|c|}
\hline \multirow{2}{*}{ Concentration, \% } & \multicolumn{2}{|c|}{ Pure Bentonite } & \multicolumn{2}{c|}{ Bentonite after sunflower oil filtration } \\
\cline { 2 - 5 } & $36^{\circ} \mathrm{C}$ & $42^{\circ} \mathrm{C}$ & $36^{\circ} \mathrm{C}$ & $42^{\circ} \mathrm{C}$ \\
\hline 0 & $48 \pm 3$ & $51 \pm 5$ & $44 \pm 6$ & $47 \pm 3$ \\
\hline 1 & $50 \pm 4$ & $50 \pm 3$ & $40 \pm 4$ & $45 \pm 3$ \\
\hline 2.5 & $51 \pm 6$ & $45 \pm 6$ & $24 \pm 6^{*}$ & $27 \pm 5^{*}$ \\
\hline 5 & $46 \pm 3$ & $40 \pm 5$ & $0^{*}$ & $0^{*}$ \\
\hline 10 & $54 \pm 2$ & $53 \pm 4$ & $0^{*}$ & $0^{*}$ \\
\hline 20 & $47 \pm 5$ & $51 \pm 4$ & $0^{*}$ & $0^{*}$ \\
\hline 50 & $43 \pm 4$ & $49 \pm 3$ & $0^{*}$ & \\
\hline
\end{tabular}

* significant difference from the control $(\mathrm{p}<0.05)$ 
Analyzing the results obtained, it can be concluded that pure bentonite had no effect on the growth of the studied bacteria. Even when bentonite was added to the medium in high concentrations, no reduction in bacterial survival was observed.

Bentonite obtained from filters after cleaning sunflower oil had a depressing effect on the growth of bacteria, both B. subtilis and B. amyloliquefaciens. If at a one-percent concentration of such bentonite in the medium, no significant differences in bacterial growth from the control were observed, then already at an increase in the concentration to $2.5 \%$, a decrease in survival was noted by $47-50 \%$ for B. amyloliquefaciens and $41-48 \%$ for B. subtilis. A further increase in the concentration of spent bentonite completely suppressed the growth of bacteria.

Obviously, this difference in the action of bentonite is associated with the processes occurring in the oil filtration process. It can be assumed that the growth of bacteria suppresses the remaining sunflower oil in the bentonite, but this is unlikely. Yes, it is known that vegetable oil is not a good enough substrate for the growth of bacteria of the genus Bacillus, however, it is not bactericidal for them.

On the other hand, bentonite is able to adsorb various substances on itself. It is logical to assume that in the process of oil purification, toxic substances are deposited on the bentonite and accumulate in it. This assumption is more likely, but requires further research.

Conclusion: pure bentonite is considered by us as a growth substrate for probiotics intended for use in industrial and farm poultry farming. It is proposed to study the possibility of using spent bentonite, after purification of sunflower oil, as a carrier for probiotic crops aimed at use in poultry farming, taking into account the use of spent bentonite in small concentrations (no more than $1 \%$ ).

The developed algorithm for designing probiotic additives assumes, as part of the module for confirming the quality of the resulting product, in the event of a negative result, the replacement of toxic components for the target strains with non-toxic ones.

It may also be necessary to adjust the formulation of the supplement in the direction of increasing the content of probiotic components.

Parameters of feeding the chickens with the use of feed additives on the basis of the studied probiotic strains.

Method of application of a feed additive based on the studied probiotic strains for birds:

- a feed additive in the amount of $1.5 \%$ of the weight of mineral feed is introduced into the diet of repair young chickens;

- in the diet of laying hens in the amount of $3 \%$ by weight of mineral feed.

This amount of feed additive introduced into the diet of poultry of different age periods of cultivation was determined by the main limiting indicator of the test product - calcium.

Feeding feed additives is carried out at all stages of the period of the poultry egg production efficiency, and in a separate periods: the rearing chickens -17 weeks (from 10 to 120 days), the contents of rearing in the shop laying hens (prekladovy period) until 21 weeks of age, the contents of laying hens: renoprotective period to 45 weeks of age, the period of operation - up to 72 weeks.

Feed mixtures of mixed feeds PK-3-51 and PK-1-0-88 developed and compiled on the basis of the applied feed products at LLC "Aksayskaya poultry farm" (Aksaysky district, Rostov region).

Composition of the feed mixture of mixed feed PK-3-51:

Young animals 6-17 weeks: corn - 30,000\%; wheat - 24,199\%; extruded soy $17,304 \%$; sunflower cake $-24,999 \%$; salt $-0.279 \%$; monocalcium phosphate $-0.725 \%$; shell flour - 1,400\%; megafos $5000-0.015 \%$; agrocele - $0.050 \%$; feed lysine $78 \%-$ $0.305 \%$; feed methionine $-0.114 \%$; mycofix select $-0.050 \%$; premix young $-0.500 \%$; vitamin $\mathrm{B}_{4}-0.060 \%$. 
In the experiment, they were introduced on the basis of the studied probiotic strains instead of the shell flour used in the conditions of the poultry farm.

The composition of the feed mixture feed PC-1-0-88:

Laying hens $17-57$ weeks.: corn - 44,558\%; wheat - 10,000\%; sunflower cake $31,000 \%$; yeast hydrolysis $-3,219 \%$; salt of $0.263 \%$; monocalcium phosphate $-0,726 \%$; Shelly flour - 9,099\%; megafos $5000-0,012 \%$; agrocele - 0,050\%; lysine feed $78 \%$ $0,333 \%$; methionine feed $-0,110 \%$; mycofix select $-0,050 \%$; premix $-0,500 \%$; vitamin $\mathrm{B}_{4}-0.080 \%$.

In the experiment, a feed additive was introduced based on the probiotic strains studied, reducing the shell flour to $6.0 \%$.

\section{Conclusions}

As a result of the research, an algorithm for obtaining new feed additives for poultry is presented, as well as the parameters of feeding chickens and the composition of feed additives with the inclusion of the studied probiotic strains are developed.

\section{References}

1. G.A. Zelenkova, I.F. Gorlov, Fodder bentonite for farm animals and a bird (ekobentokorm) TU 9283-199-10514645-13-2013 specifications

2. A. Pahomova, S. Halász, A. Pakhomov et al., E3S Web of Conferences, 217, 06002 (2020)

3. A. Zelenkov, G. Zelenkova, S. Tresnitskii et al., E3S Web of Conferences, 217, 09010 (2020)

4. A. Pahomova, S. Halász, V. Fedorchuk, G. Zelenkova, A. Pakhomov, E3S Web of Conferences, 210, 11003 (2020)

5. A. Zelenkov, A. Ermakov, G. Zelenkova et al., E3S Web of Conferences 135, 01088 (2019)

6. V. Berikashvili, K. Sokhadze, E. Kachlishvili, V. Elisashvili, ML. Chikindas, Probiotics Antimicrob Proteins, 10(4), 755 (2018)

7. A. Zelenkov, A. Ermakov, G. Zelenkova et al., IOP Conf. Series: Earth and Environmental Science, 403 (1), 012020 (2019)

8. A. Zelenkov, G. Zelenkova, A. Ermakov et al., E3S Web of Conferences 164, 06032 (2020)

9. A. Pahomova, A. Pakhomov et al. Vitamin and mineral adsorption food additives for poultry and the method of its application (A23K 50/70, A23K 20/158, A23K 20/174) 